\title{
End points in pulmonary arterial hypertension: the way forward
}

\author{
A. Peacock*, R. Naeije ${ }^{\#}$, N. Galié ${ }^{\top}$, J.T. Reeves ${ }^{+}$
}

End points in pulmonary arterial hypertension: the way forward. A. Peacock, R. Naeije, N. Galié, J.T. Reeves. (C) ERS Journals Ltd 2004.

ABSTRACT: Pulmonary arterial hypertension is a rare disease of poor prognosis.

Despite its rarity $>1,000$ patients have been randomised in placebo-controlled trials using novel therapies, including prostacyclin analogues, endothelin receptor antagonists and, most recently, phosphodiesterase 5 inhibitors. Nearly all of these trials have used exercise capacity, measured by the unencouraged 6-min walking distance, as the primary end point and a variety of other measurements as secondary end points. This approach has been productive, leading to the licensing of a number of effective treatments. Future clinical trials, however, will probably assess drug combinations, make comparisons between drugs and include less severely ill patients. It is, therefore, timely to examine the end points used.

The authors discussed the various end points that have been used in the past and possible end points that might be used in the future. End points considered included measurements of: exercise capacity, haemodynamics, quality of life, imaging of the right heart and circulation, and chemical markers of pulmonary hypertension.

Many of these show promise but will have to be used in parallel and compared with conventional end points such as the 6-min walking distance before their value can be demonstrated convincingly to the regulatory authorities.

Eur Respir J 2004; 23: 947-953.
*Scottish Pulmonary Vascular Unit, Western Infirmary, Glasgow, UK. " Dept of Cardiology, Erasme University Hospital, Brussels, Belgium. "Institute of Cardiology, University of Bologna, Bologna, Italy. ${ }^{+}$University of Colorado Medical Center, Denver, CO, USA.

Correspondence: A. Peacock, Scottish Pulmonary Vascular Unit, Western Infirmary, Glasgow, G61 2SW, UK.

Fax: 441412116334

E-mail: apeacock@udcf.gla.ac.uk

Keywords: Biological markers exercise physiology

haemodynamics

imaging

pulmonary hypertension

quality of life

Received: October 302003

Accepted after revision: December 102003
Pulmonary arterial hypertension (PAH) is a disease of the peripheral pulmonary arteries of varying patho-aetiology. Interestingly, whatever the aetiology, the histology of the vessels is similar, prompting a unified approach to treatment. Initial success was achieved with anticoagulants and calcium channel blockers [1], but calcium channel blockers are effective in $<10 \%$ of patients. Later, it was found that continuous intravenous epoprostenol was effective even in those who could not use the calcium channel blockers [2]. In 2001 and $2002,>1,000$ patients with PAH were entered into placebocontrolled trials [3-7]. Nearly all of these trials have used the unencouraged 6-min walking distance and resting haemodynamics as end points. Results were significant, but not dramatic in physiological terms, with mean increases in 6-min walking distance ranging $17-72 \mathrm{~m}$, and decreases in mean pulmonary artery pressure $(P$ pa) never exceeding a few millimetres of mercury. Although patients reported improvement, survival remains limited, and none of the newly introduced therapies has yet been shown to reverse the pathological process.

Some physicians monitoring clinical trials consider that the end points used may not best adequately represent the effectiveness of therapy. It is likely that placebo-controlled trials will become unacceptable and, in the future, more backto-back comparisons of different therapies and also comparisons of different combinations of therapy will be introduced. In order to convince patients, physicians, funding agencies and regulatory bodies of the value of treatments which are often expensive, it is worth considering whether other end points should be examined that more adequately describe the changes that occur. From the patients', and increasingly also the regulatory agencies', perspective, quality of life is one of

Previous articles in this Series: No. 1: Humbert M, Trembath RC. Genetics of pulmonary hypertension: from bench to bedside. Eur Respir J 2002; 20: 741-749. No. 2: Galiè N, Manes A, Branzi A. The new clinical trials on pharmacological treatment in pulmonary arterial hypertension. Eur Respir J 2002: 20: 1037-1049. No. 3: Chemla D, Castelain V, Hervé P, Lecarpentier Y, Brimioulle S. Haemodynamic evaluation of pulmonary hypertension. Eur Respir J 2002; 20: 1314-1331. No. 4: Eddahibi S, Morrell N, d'Ortho M-P, Naeije R, Adnot S. Pathobiology of pulmonary arterial hypertension. Eur Respir J 2002; 20: 1559-1572. No. 5: Widlitz A, Barst RJ. Pulmonary arterial hypertension in children. Eur Respir J 2003; 21:155-176. No. 6: Moloney ED, Evans TW. Pathophysiology and pharmacological treatment of pulmonary hypertension in acute respiratory distress syndrome. Eur Respir J 2003; 21: 720-727. No. 7: Barberà JA, Peinado VI, Santos S. Pulmonary hypertension in chronic obstructive pulmonary disease. Eur Respir J 2003; 21: 892-905. No. 8: Dorfmüller P, Perros F, Balabanian K, Humbert M. Inflammation in pulmonary arterial hypertension. Eur Respir J 2003; 22: 358-363. No 9: Maggiorini M, Velarde F-L. High-altitude pulmonary hypertension: a pathophysiological entity to different diseases. Eur Respir J 2003; 22: 1019-1025. No 10: Dartevelle P, Fadel E, Mussot S, et al. Chronic thromboembolic pulmonary hypertension. Eur Respir J 2004; 23: $637-648$.

For editorial comments see page 799. 
the most important measures of the success or failure of a new treatment. However, physicians treating PAH will not be satisfied with improvements in quality of life alone, and a specific questionnaire has not been validated in PAH patients. The physicians will require to see physiological changes accompanying the change in quality of life, whether these be changes in pulmonary haemodynamics, exercise physiology, biological markers or cardiopulmonary morphology. At the End Points Meeting held in Gleneagles, UK, May 1-4, 2003, experts on quality of life, imaging, exercise physiology, pulmonary haemodynamics and the hormonal changes associated with PAH were collected together from all over the world. There were also contributions from the regulatory bodies. The aim of the meeting was to consider the end points that have been used in the past and also to consider end points that might be used in the future. The definition of "end point" used was "a measurement used by investigators conducting a drug trial to determine whether patients with pulmonary arterial hypertension were benefited by drug administration". The following is a summary of the conclusions of the workshops that considered each of these topics.

\section{Regulatory issues}

The decision on appropriate end points for clinical trials in PAH needs to take into account the requirements of the regulatory agencies that are the ultimate referees for the approval of a treatment for a given indication.

In the process of decision-making for the implementation of new trials for PAH, the two main points are trial design and choice of appropriate primary and secondary reinforcing end points $[7,8]$.

\section{Trial design}

Following approval of an oral drug (bosentan) for the treatment of New York Heart Association Functional Class (NYHAFC) III PAH patients and the availability of new oral compounds to be tested, a range of questions need to be addressed. 1) Are placebo-controlled studies still possible in PAH? 2) Are noninferiority studies feasible in PAH? 3) Are withdrawal studies ethical in PAH?

\section{Placebo-controlled studies}

Currently four treatments for PAH patients are officially approved by regulatory agencies, the US Food and Drug Administration (FDA) and the European Agency for the Evaluation of Medicinal Products (EMEA): intravenous epoprostenol for NYHAFC III and IV primary pulmonary hypertension (FDA and EMEA) [2]; subcutaneous treprostinil in NYHAFC II [3], III and IV PAH (FDA); oral bosentan in NYHAFC III PAH (FDA and EMEA) [6]; and inhaled iloprost in NYHAFC III PAH (EMEA) [5]. Only epoprostenol treatment has been shown, in a controlled clinical trial, to improve survival [2]. Treprostinil, iloprost and bosentan treatments have reduced the rate of clinical events but not mortality in the 3-4 months of the randomised trials $[3,5,6]$. The patient population enrolled in these last three studies was less compromised as compared to that in the epoprostenol study, but the reduced rate of events, small sample size and short duration of the studies have clearly underpowered these trials in detecting effects on mortality.

From the ethical and methodological point of view, experts now believe that a mortality study in PAH (NYHAFC III and IV) can be performed only with intravenous epoprostenol as comparator in countries in which this treatment is approved and available.

It is less clear whether a placebo-controlled study whose primary end point is exercise capacity assessed after 3 months of a randomised treatment would be acceptable. The points in favour of the continuation of the use of placebo include the following: 1) no prognostic superiority has been demonstrated by any new drug over the 3-4-month randomised trial periods (mortality ranging $1-3 \%$, corresponding to $4-12 \% \cdot \mathrm{yr}^{-1}$ ); 2 ) the setting of a controlled clinical trial "protects" patients who can be shifted to already approved treatments in case of deterioration; 3) NYHAFC II patients have been involved only marginally in clinical trials in PAH and may be included in placebo-controlled studies; and 4) a consistent proportion of patients with PAH fail to respond to the currently available treatments, and, therefore, it is not desired that hurdles be too high for the investigation of "new" drugs.

In contrast, arguments against the continuation of placebocontrolled studies include the following: 1) it is not ethical to expose patients to a 3-month period of placebo that has been shown to produce, in some cases, symptomatic and clinical deterioration; 2) NYHAFC II patients are a "minority" in the population observed in clinical practice; and 3) the current priority should be the comparison of new treatments with approved ones, and noninferiority studies should be implemented

\section{Noninferiority studies}

Noninferiority comparative studies can be an alternative to superiority placebo-controlled studies if the latter are considered inappropriate for ethical reasons. Superiority comparative studies between active therapies would be difficult to perform in a rare disease such as PAH because the sample size needed is usually quite large. The objective of a noninferiority study is the demonstration that there is no significant difference between the two compounds for a given end point. The feasibility of noninferiority studies in PAH is related to the following points. 1) Noninferiority studies can be performed only using the primary end points already investigated. In the case of PAH, this would be the 6-min walking distance if the comparator is bosentan. This would seem to restrict the use of new end points, but these could be used in parallel with the 6-min walking distance. 2) Noninferiority studies require an identical setting (inclusion criteria, exclusion criteria, patient population, study protocol, etc.) to the pivotal study of the "comparator". 3) The sample size would need to be quite high ( $>500$ patients) if the end point is the six-min walking distance and the comparator is bosentan. 4) The risks and costs for a pharmaceutical company are much higher compared to a superiority study.

\section{Withdrawal studies}

Withdrawal studies are suggested by regulatory agencies for different reasons, e.g. when the pivotal trials have not shown a "clinically relevant" benefit or more consistent proof of efficacy is required. However, in a life-threatening disease such as PAH, a withdrawal study seems to be inappropriate for the following reasons: 1) in $\mathrm{PAH}$, no drugs have been shown to induce a consistent modification of the disease process and therefore there is no reason to believe that the withdrawal of an effective drug would not induce a deterioration; 2) as a consequence, the end point of this study would be an assessment of deterioration and this could be considered to be against basic medical principles (primum non nocere); 3 ) nobody can guarantee the reversibility of deterioration in patients with PAH, even after the reinstitution of a previous 
treatment; and 4) the approval of institutional review boards, for ethical reasons, and patients' acceptance of such trials are questionable

\section{Primary and secondary reinforcing end points according to the requirements of the regulatory agencies}

Regulatory agencies currently accept as "primary" only clinical end points such as exercise capacity, time to clinical worsening and mortality. Usually, pathophysiological parameters such as haemodynamics are considered "secondary".

In PAH, the assessment of exercise capacity using the 6-min walk test may still be the "best option" for the primary end point, especially since it allows comparison with results from previous trials. The 6-min walking distance could be improved by utilisation of an index that includes the distance walked and the Borg dyspnoea index or the level of arterial desaturation during the exercise. A correction for age and body weight could prove useful. Obviously, these new indices and other end points should be validated in prospective studies that investigate their superiority compared to simply the walked distance. It is important that the "clinical relevance" of a given improvement in the distance walked is defined a priori in the protocol of a study to avoid inconclusive discussions at the end of the trial. As the "clinical relevance" of a given improvement is somewhat arbitrary, it can be defined according to the treatment effect obtained with treatments already approved.

The use of quality-of-life questionnaires as "primary" end point has been proposed, but there are several doubts as to their applicability in PAH, in particular because no validation has been provided in this specific clinical setting.

Time to clinical worsening as a combined end point requires standardisation to make it more objective and comparable. This parameter is usually defined by a combination of death, hospitalisations due to worsening of PAH and escalation of treatments (need for epoprostenol or transplantation). The latter two events are influenced by the judgement of the attending physician and should be supported by some "objective" findings, such as predefined cut-off levels for exercise capacity and haemodynamic parameter deterioration.

Haemodynamic parameters have been considered traditionally as "secondary" reinforcing end points, based on their prognostic value [9], and this concept has been accepted by regulatory agencies, but resting haemodynamics are likely, at best, to give an incomplete picture of the damaged pulmonary vessels in PAH. Haemodynamics under conditions of stress, such as exercise, dobutamine or leg raising, are likely to be more useful. The possibility of using selected echocardiographic parameters as a substitute for invasive haemodynamic measurements should also be explored. Indeed, some echocardiographic and Doppler parameters, such as Dopplerderived cardiac output, right ventricular (RV) (Tei) index, pericardial effusion size, etc., have been shown, in recent studies, to be of value prognostically [10] and in assessing therapeutic changes in patients with PAH $[11,12]$.

The usefulness of biological end points, such as levels of B-type natriuretic peptide (BNP), troponin, endothelin, etc., in clinical trials have still to be tested and validated in clinical studies before they can be proposed to regulatory agencies.

\section{Possible ways forward}

\section{Imaging}

Magnetic resonance imaging (MRI) has been introduced, in recent years, for the assessment of ventricular mass and cardiac volumes and measurements of absolute flow and velocity in the pulmonary circulation [13-17]. Although more expensive and complex than echocardiography, MRI may ultimately reduce the number of observations needed to verify a research hypothesis. This is because of the improved (over echocardiography) reproducibility of its results. However, new generations of software need to be developed, permitting semiautomatic evaluation of acquired data, in order to reduce the excessive time currently needed for even relatively simple measurements. In addition, costs and the time required for the procedure need to be considered in the comparison with established methods.

Spiral computerised tomography using recent multielement technology provides the highest resolution of all the imaging methods. However, it gives less insight into haemodynamics, and is likely to be superseded by MRI, which provides both structural and functional information.

The evaluation of imaging in assessing pulmonary hypertension has come almost entirely from echocardiographic studies in primary pulmonary hypertension [10-12, 18-25]. The data indicate that some variables potentially useful as end points reflect chronic consequences of $\mathrm{PAH}$, rather than being measurements of instantaneous haemodynamics. The following are examples of this. 1) Elevation of right atrial pressure by assessment of the presence and score of pericardial effusion, as well as measurement of right atrial area/volume or the dimensions of the inferior vena cava. 2) RV dysfunction assessed by calculating Doppler indices of ventricle performance or, alternatively, measuring the duration and flow velocity pattern of RV ejection. Surrogate assessment of RV ejection fraction by tissue Doppler imaging or M-mode assessment of tricuspid annular systolic motion could be of value. 3) Decreased left ventricular preload by assessment of left ventricular diastolic eccentricity index or end diastolic area/volume, as well as by decreased left ventricular early diastolic filling velocity. Interestingly, it was the improvement in left ventricular early diastolic filling which seemed best to reflect the effects of treatment of patients with PAH according to existing evidence [12].

Tissue Doppler imaging may further simplify assessment of the dynamics of the heart and may provide assessment of indices of RV function from a single trace. Recent experimental data suggest that myocardial acceleration during isovolumic RV contraction is load-independent and strongly correlated with end-systolic RV elastance, the best available measure of its contractility

\section{Haemodynamics}

Right heart catheterisation measurements of $P$ pa, pulmonary artery occlusion pressure $(P$ pa,occ $)$ and blood flow $\left(Q^{\prime}\right)$, with calculation of pulmonary vascular resistance, are correlated to clinical state, NYHAFC, exercise capacity and prognosis [2, 9, 26-28], but these correlations are rather loose when the measurements are performed only at rest. A single point measurement may under- or overestimate changes in the functional state of the pulmonary circulation, primarily because the inherent assumptions of zero crossing of the $\left(P\right.$ pa- $P$ pa,occ) $/ Q^{\prime}$ relationship are not met [29, 30, 31]. This error can be minimised by defining resistance from a multipoint pressure/flow line [29]. For example, recent studies showed that improvement in exercise capacity with prostacyclin therapy in PAH patients may not be associated with significant changes in pulmonary haemodynamics at rest, whereas resistance defined by a multipoint $(P \mathrm{pa}-P$ pa,occ $) / Q^{\prime}$ plot shows a significant decrease [30]. Multiple points can be 
obtained by increasing cardiac output with exercise [30] or a low-dose infusion of dobutamine [31].

In addition, mean $P$ pa and $Q^{\prime}$ determinations may be insufficient to measure RV afterload [32], since, in addition to vascular resistance, afterload involves elastance and wave reflection. Although afterload can be estimated by pulmonary arterial input impedance (the ratio of pulsatile $P$ pa to pulsatile $Q^{\prime}$ ), impedance determination requires spectral analysis, complicated mathematics and high-fidelity technology [32, 33], which is unavailable in most catheterisation laboratories. Therefore, the clinical relevance of impedance determinations is unclear. RV afterload can be indirectly evaluated by $P$ pa and $Q^{\prime}$ waveform analysis [34-36], but its diagnostic value remains controversial [37].

Continuous 24-h monitoring of $P$ pa shows the effects of daily life (postural changes, exercise and sleep) on pressure [38], and therefore provides a novel index of afterload. However, the method uses micromanometer-tipped catheters and is expensive and invasive, and requires a high level of expertise. Therefore, it can be considered only in a limited number of reference centres, where results can be correlated with other, more available, techniques.

With the addition of these newer techniques and methods of analysis, the current tendency to omit invasive haemodynamics, even as a secondary end point, appears premature.

\section{Exercise capacity}

The most common symptoms of patients with PAH, namely shortness of breath and fatigue, occur predominantly during exercise. These symptoms result from the combined effects of decreased oxygen delivery to the tissues, increased physiological dead space and arterial hypoxaemia, together causing a decreased peak or maximum oxygen consumption, an early anaerobic threshold and increased ventilatory equivalents. Accordingly, the physiological severity of PAH can be quantified by measurements of ventilation, oxygen consumption and carbon dioxide production at progressively increased workload. Several such cardiopulmonary exercise testing (CPET)-derived measurements have been shown to be correlated to outcome [39-42]. One of the best indicators of disease severity in PAH patients appears to be elevation of ventilation/ carbon dioxide production, measured at the anaerobic threshold [39-43].

The 6-min walking distance, used as primary end point in randomised controlled trials, is nothing more than a simpler, cheaper and better-tolerated submaximal exercise surrogate of CPET for evaluating exercise capacity. However, there is very little experience with CPET in randomised controlled trials in PAH patients. In a recent trial of the oral prostacyclin derivative beraprost in $\mathrm{PAH}$, the 6-min walking distance improved at 3 and 6 months, whereas there were no concomitant significant changes in CPET indices [44]. Similar results have been preliminarily shown in a randomised study with the endothelin receptor antagonist sitaxentan [45]. These surprising results, which might be related to unknown causes, including insufficient quality control in participating centres, deserve further investigation.

\section{Quality of life}

Until now, the impact of PAH on quality of life has been evaluated by generic health status measures such as the 36-item Short-Form Health Survey [46], Nottingham Health Profile [47], European quality of life [scale] [48] and Living with Heart Failure Minnesota questionnaire [49]. Although the results of these measures improve or deteriorate along with changes in clinical condition, functional state and exercise capacity $[2,3,5]$, there is a concern about validation, sensitivity and possible failure to assess those issues that are of major concern to the patient [50]. Accordingly, efforts are being made to collect, directly from patients, information on impairments (symptoms), disability (functioning), handicap and utility $[50,51]$. It is important to be clear about how these items differ, how they relate to each other and their relative value in determining the impact of disease [52-57]. The availability of a PAH-specific quality-of-life instrument would provide the patient-relevant end point that is currently lacking.

\section{Biological markers}

Markers of endothelial cell and/or platelet dysfunction in PAH include endothelin-1 [58-62], prostaglandins, thromboxanes [63, 64], nitric oxide [65, 66], von Willebrand factor $[67,68]$, D-dimers [69], serotonin [70, 71], adhesion molecules, cytokines and chemokines [72]. Although these markers probably have pathophysiological or prognostic relevance in PAH, the trials suffer from small study populations and thus require confirmation. Furthermore, interventions which directly alter levels of endothelins, prostaglandins, or their receptors, reduce their interest as markers for monitoring treated patients.

Markers of heart failure (A-type natriuretic peptide, BNP and cyclic guanosine monophosphate (cGMP)) may be more relevant to addressing prognosis and improvements with therapy [73, 74] than assessing disease state. Interestingly, $\mathrm{N}$-terminal pro-BNP (the biologically inactive alternative) is more stable than is plasma BNP, and is a potentially useful marker. Whether heart failure markers are useful early in the natural history of the disease remains to be demonstrated.

Chronic leakage of troponin $\mathrm{T}$ (presumably from RV myocytes) is a high-sensitivity test indicative of ongoing damage to the right ventricle and is related to poor survival in PAH [75].

Serum uric acid levels correlate inversely with cardiac index and positively with total pulmonary resistances. The levels correlate inversely with survival and fall with haemodynamic improvement [76]. However, uric acid is affected by variables including drugs, tissue perfusion, decreased glomerular filtration and hypoxia.

Markers of the effects of PAH which can be measured in urine (i.e. cGMP, prostaglandins, thromboxanes and isoprostanes [77]) or in exhaled air or its condensate (nitric oxide) are potentially useful, although validation studies are needed.

\section{Clinical end points}

Signs and symptoms in PAH are well defined and limited in number, and, accordingly, a 15-item clinical score has been developed, and implemented in one clinical trial of PAH treatment [3]. This score proved to be as sensitive to the active treatment as the 6-min walking distance [3] and would be worth considering in future clinical studies.

Clinical events such as death, hospitalisation for right heart failure and the requirement for alternative treatments have been used as secondary, often combined, end points. In three different trials, the active treatment led to a reduction in these clinical events after 3-4 months $[2,5,6]$. A combined end point of clinical events has the potential of a primary end point. 


\section{Conclusions and recommendations: the end point}

The present working group on end points, with participants from Belgium, the UK, France, Germany, Ireland, Italy, Switzerland and the USA, drew conclusions and made recommendations relative to the evaluation of patients with PAH.

Perhaps the main result of the present conference was that those evaluating the treatment of PAH were not completely satisfied with the current end points. For example, a given end point was: 1) insensitive (poor signal-to-noise ratio), 2) inaccurate (did not reflect the status of the disease), 3) incomplete (ignored important components of the disease), 4) expensive/time-consuming/complicated (not generally applicable to a population of patients, could not be frequently repeated and/or not appropriate for use by many clinicians), 5) transient (reflected a moment in time and was too labile to represent the overall picture), 6) subjective (sensitive to mood or bias of patient or investigator), and 7) required a longer evaluation period than was practically available during the trial.

Conversely, for broad application to a population, characteristics of an "ideal" marker for PAH might include the following: 1) it should be heart- or lung-specific, 2) it should be abnormal in PAH, 3) sample collection should be simple, 4) the marker should be easy to measure (ideally bedside measurement), 5) values should be reproducible, 6) values should follow the course of the disease (i.e. increasing if patients deteriorate and falling if patients improve), and 7) abnormal values should be indicative of poor survival.

In the absence of an "ideal end point/marker", recommendations for improvement of future studies could involve the following items. 1) Validation studies might include longitudinal analyses in stable and unstable patients with or without targeted therapies. 2) Strategies should be devised to improve the sensitivity of given end points, and consideration should be given to the analysis of several markers in parallel, which might also improve sensitivity. 3) More emphasis should be placed on the early stages of disease, with end points/markers tailored to this stage. 4) Strategies which give rapid results and allow immediate use of the information should be emphasised. 5) There should be continued development of new technologies and methods of analysis, with emphasis on sensitive predictors of prognosis. 6) If legally possible, plasma and other biological samples should be stored, with the patient's consent, in well-characterised PAH populations to be available for tests devised in the future. 7) More individual data should be shared among investigators to facilitate more rapid progress.

General recommendations are as follows. 1) Working groups should be convened regularly because they are effective in clarifying and discussing the problems, proposing possible solutions and developing collaboration to bring about solutions. 2) Small subgroups of experts dealing with specific problems result in conclusions, which are then brought back to the general group. 3) Publication of the result of deliberations provides broader dissemination of information and a benchmark for the future.

\footnotetext{
Acknowledgements. Members of the expert groups: Regulatory: N. Galiè (chair; Institute of Cardiology, University of Bologna, Bologna, Italy), P. Corris (Transplant Unit, Freeman Hospital, Newcastle, UK) and M. Rainisio (Actelion Pharmaceuticals, Allschwil, Switzerland); Imaging: A. Torbicki (chair; National Institute Lung Diseases, Warsaw, Poland), R. Coulden (Pulmonary Vascular Diseases Unit, Papworth
}

Hospital, Papworth Everard, UK), A. Peacock (Scottish Pulmonary Vascular Unit, Western Infirmary, Glasgow, UK) and M. Sproule (Radiology, Scottish Pulmonary Vascular Unit, Western Infirmary, Glasgow, UK); Haemodynamics: R. Naeije (chair; Faculty of Medicine, University of Brussels, Brussels, Belgium), P. Hervé (Medecin Pneumologue, Hôpital Antoine Béclère, Paris, France), M. Maggiorini (University Hospital, Zurich, Switzerland) and G. Simonneau (Hôpital Antoine Béclère, Paris, France); Exercise capacity: L. Rubin (chair; Pulmonary Vascular Centre, University of California, San Diego, CA, USA), M. Hoeper (Respiratory Medicine, Hanover Medical School, Hanover, Germany), R. Oudiz (Center for Pulmonary Hypertension, University of California, Los Angeles, CA, USA), J. Barbera (Dept of Pneumology, Hospital Clinic, Barcelona, Spain) and O. Sitbon (Hôpital Antoine Béclère, Paris, France); Quality of life: S.P. Gaine (chair; Mater Misericordiae, Dublin, Ireland), J. PepkeZaba (Pulmonary Vascular Diseases Unit, Papworth Hospital, Papworth Everard, UK), S.P. McKenna (Galen Research, Manchester, UK) and J. Reeves (University of Colorado Health Sciences, Denver, CO, USA); Hormonal and blood studies: M. Humbert (chair; Hôpital Antoine Béclère, Paris, France), M. Delcroix (Catholic University of Leuven, Leuven, Belgium), D. Langleben (McGill University, Montreal, Canada) and H. Olschewski (Medizinische Klinik II, Justus Liebig University Giessen, Gießen, Germany).

\section{References}

1. Rich S, Kauffmann E, Levy PS. The effects of high doses of calcium channel blockers on survival in primary pulmonary hypertension. N Engl J Med 1992; 327: 76-81.

2. Barst RJ, Rubin LJ, Long WA, et al. A comparison of continuous intravenous epoprostenol (prostacyclin) with conventional therapy for primary pulmonary hypertension. $N$ Engl J Med 1996; 334: 296-302.

3. Simonneau G, Barst RJ, Galie N, et al. Continuous subcutaneous infusion of teprostinil, an epoprostenol analogue, in patients with pulmonary arterial hypertension: a double-blind randomised controlled trial. Am J Respir Crit Care Med 2002; 165: 800-804.

4. Galie N, Humbert M, Vachiery JL, et al. Effect of beraprost sodium, an oral epoprostenol analogue, in patients with pulmonary arterial hypertension: a randomised doubleblind, placebo-controlled trial. J Am Coll Cardiol 2002; 39: 1496-1502.

5. Olscheswki H, Simonneau G, Galie N, et al. Inhaled iloprost for severe pulmonary hypertension. New Engl J Med 2002; 347: 1119-1123.

6. Rubin RJ, Badesch DB, Barst RJ, et al. Bosentan in patients with pulmonary artery hypertension: a randomised placebo controlled, multicentre study. N Engl J Med 2002; 346: 896903.

7. Galie N. Do we need controlled clinical trials in pulmonary arterial hypertension? Eur Respir J 2001; 17: 1-3.

8. Galie N, Manes A, Branzi A. The new clinical trials on pharmacological treatment in pulmonary arterial hypertension. Eur Respir J 2002; 20: 1037-1049.

9. D'Alonzo GE, Barst RJ, Ayres SM, et al. Survival in patients with primary pulmonary hypertension. Results from a national prospective registry. Ann Intern Med 1991; 115: 343-349.

10. Raymond RJ, Hinderliter AL, Willis PW, et al. Echocardiographic predictors of adverse outcomes in primary pulmonary hypertension. J Am Coll Cardiol 2002; 39: 1214-1219. 
11. Hinderliter $\mathrm{AL}$, Willis $\mathrm{PW}$, Barst RJ, et al. Effects of long-term infusion of prostacyclin (epoprostenol) on echocardiographic measures of right ventricular structure and function in primary pulmonary hypertension. Circulation 1997; 95: 1479-1486.

12. Galie N, Hinderliter AL, Torbicki A, et al. Effects of the oral endothelin-receptor antagonist bosentan on echocardiographic and Doppler measures in patients with pulmonary arterial hypertension. J Am Coll Cardiol 2003; 41: 1380-1386.

13. Saba TS, Foster J, Cockburn M, Cowan M, Peacock AJ. Ventricular mass index using magnetic resonance imaging accurately estimates pulmonary artery pressure. Eur Respir $J$ 2002; 20: 1519-1524.

14. Apfel HD, Shen Z, Gopal AS, et al. Quantitative three dimensional echocardiography in patients with pulmonary hypertension and compressed left ventricles: comparison with cross sectional echocardiography and magnetic resonance imaging. Heart 1996; 76: 350-354.

15. Boxt LM, Katz J, Kolb T, Czegledy FP, Barst RJ. Direct quantitation of right and left ventricular volumes with nuclear magnetic resonance imaging in patients with primary pulmonary hypertension. J Am Coll Cardiol 1992; 19: 15081515.

16. Bellenger NG, Grothues F, Smith GC, Pennell DJ. Quantification of right and left ventricular function by cardiovascular magnetic resonance. Herz 2000; 25: 392-399.

17. Markiewicz W, Sechtem U, Higgins CB. Evaluation of the right ventricle by magnetic resonance imaging. Am Heart $J$ 1987; 113: 8-15.

18. Hinderliter AL, Willis PW, Long W, et al. Frequency and prognostic significance of pericardial effusion in primary pulmonary hypertension. Am J Cardiol 1999; 84: 481-484, A10.

19. Meluzin J, Spinarova L, Bakala J, et al. Pulsed Doppler tissue imaging of the velocity of tricuspid annular systolic motion; a new, rapid, and non-invasive method of evaluating right ventricular systolic function. Eur Heart $J$ 2001; 22: 340348.

20. Naeije R, Torbicki A. More on the noninvasive diagnosis of pulmonary hypertension: Doppler echocardiography revisited. Eur Respir J 1995; 8: 1445-1449.

21. Nootens M, Wolfkiel CJ, Chomka EV, Rich S. Understanding right and left ventricular systolic function and interactions at rest and with exercise in primary pulmonary hypertension. Am J Cardiol 1995; 75: 374-377.

22. Tei C, Dujardin KS, Hodge DO, et al. Doppler echocardiographic index for assessment of global right ventricular function. J Am Soc Echocardiogr 1996; 9: 838-847.

23. Vogel M, Schmidt MR, Kristiansen SB, et al. Validation of myocardial acceleration during isovolumic contraction as a novel noninvasive index of right ventricular contractility: comparison with ventricular pressure-volume relations in an animal model. Circulation 2002; 105: 1693-1699.

24. Yeo TC, Dujardin KS, Tei C, Mahoney DW, McGoon MD, Seward JB. Value of a Doppler-derived index combining systolic and diastolic time intervals in predicting outcome in primary pulmonary hypertension. Am J Cardiol 1998; 81: $1157-1161$.

25. Eysmann SB, Palevsky HI, Reichek N, Hackney K, Douglas PS. Two-dimensional and Doppler-echocardiographic and cardiac catheterization correlates of survival in primary pulmonary hypertension. Circulation 1989; 80: 353-360.

26. Miyamoto S, Nagaya N, Satoh T, et al. Clinical correlates and prognostic significance of 6-minute walk test in patients with pulmonary hypertension. Comparison with cardiopulmonary exercise testing. Am J Respir Crit Care Med 2000; 161: 487-492.

27. Sitbon $\mathrm{O}$, Humbert $\mathrm{M}$, Nunes $\mathrm{H}$, et al. Long-term intravenous epoprostenol infusion in primary pulmonary hypertension: prognostic factors and survival. $\mathrm{J} \mathrm{Am} \mathrm{Coll}$ Cardiol 2002; 40: 780-788.

28. McLaughlin V, Shillington A, Rich S. Survival in primary pulmonary hypertension. The impact of epoprostenol therapy. Circulation 2002; 106: 1477-1482.

29. McGregor M, Sniderman A. On pulmonary vascular resistance: the need for more precise definition. $\mathrm{Am}$ J Cardiol 1985; 55: 217-221.

30. Castelain V, Chemla D, Humbert M, et al. Pulmonary artery pressure-flow relations after prostacyclin in primary pulmonary hypertension. Am J Respir Crit Care Med 2002; 165: 338340.

31. Abdel Kafi S, Mélot C, Vachiéry JL, Brimioulle S, Naeije R. Partitioning of pulmonary vascular resistance in primary pulmonary hypertension. J Am Coll Cardiol 1998; 31: 13721376.

32. Laskey W, Ferrari V, Palevsky H, Kussmaul W. Pulmonary artery hemodynamics in primary pulmonary hypertension. J Am Coll Cardiol 1993; 21: 406-412.

33. Reeves JT, Groves BM, Turkevitch D, Morrisson DA, Trapp JA. Right ventricular function in pulmonary hypertension. In: Pulmonary Vascular Physiology and Pathophysiology. Weir EK, Reeves JT, eds. Lung Biology in Health and Disease. Vol. 38. New York, NY, Marcel Dekker, 1989; pp. $325-351$

34. Nakayama Y, Nakanishi N, Sugimachi M, et al. Characteristics of pulmonary artery pressure waveform for differential diagnosis of chronic pulmonary thromboembolism and primary pulmonary hypertension. J Am Coll Cardiol 1997; 29: 1311-1316.

35. Nakayama Y, Sugimachi M, Nakanishi, et al. Noninvasive differential diagnosis between chronic pulmonary thromboembolism and primary pulmonary hypertension by means of Doppler ultrasound measurement. $\mathrm{J} \mathrm{Am}$ Coll Cardiol 1998; 31: 1367-1371.

36. Nakayama $\mathrm{Y}$, Nakanishi $\mathrm{N}$, Hayashi $\mathrm{T}$, et al. Pulmonary artery reflection for differentially diagnosing primary pulmonary hypertension and chronic pulmonary thromboembolism. J Am Coll Cardiol 2001; 38: 214-218.

37. Castelain V, Herve P, Lecarpentier Y, Duroux P, Simonneau G, Chemla V. Pulmonary artery pulse pressure and wave reflection in chronic pulmonary thromboembolism and primary pulmonary hypertension. J Am Coll Cardiol 2001; 37: 1085-1092.

38. Raeside DR, Chalmer G, Clelland J, Madhok R, Peacock AJ. Pulmonary artery pressure variation in patients with connective tissue disease: 24 hour ambulatory pressure monitoring. Thorax 1998; 53: 857-862.

39. Sun X-G, Oudiz RJ, Hansen JE, Wasserman K. Exercise pathophysiology in primary pulmonary vascular hypertension. Circulation 2001; 104: 429-435.

40. Riley MS, Porszasz J, Engelen MP, Brundage BH, Wasserman K. Gas exchange responses to continuous incremental cycle ergometry exercise in primary pulmonary hypertension in humans. Eur J Appl Physiol 2000; 83: 63-70.

41. Wensel R, Opitz CF, Anker SD, et al. Assessment of survival in patients with primary pulmonary hypertension: importance of cardiopulmonary exercise testing. Circulation 2002; 106: $319-324$

42. Wax D, Garofano R, Barst RJ. Effects of long-term infusion of prostacyclin on exercise performance in patients with primary pulmonary hypertension. Chest 1999; 116: 914-920.

43. Raeside DA, Smith A, Brown A, et al. Pulmonary artery pressure measurement during exercise testing in patients with suspected pulmonary hypertension. Eur Respir J 2000; 16 : 282-287.

44. Barst RJ, McGoon M, McLaughlin V, et al. Beraprost therapy for pulmonary arterial hypertension. $\mathrm{J}$ Am Coll Cardiol 2003; 41: 2119-2125.

45. Barst RJ, Langleben D, Frost A, et al. Sitaxsentan therapy for pulmonary arterial hypertension. Am J Respir Crit Care Med 2004; 169: 441-447.

46. Ware JE Jr, Sherbourne CD. The MOS 36-item Short-Form Health Survey (SF-36). I. Conceptual framework and item selection. Med Care 1992; 30: 473-483. 
47. Hunt SM, McEwen J, McKenna SP. Measuring Health Status. London, Croom Helm, 1986.

48. Anon. EuroQol - a new facility for the measurement of health-related quality of life. The EuroQol Group. Health Policy 1990; 16: 199-208.

49. Rector TS, Cohn JN. Assessment of patient outcome with the Minnesota Living with Heart Failure questionnaire: reliability and validity during a randomized, double-blind, placebo-controlled trial of pimobendan. Am Heart J 1992; 124: 1017-1025.

50. McKenna SP, Doward LC, Kohlmann T, et al. International development of the Quality of Life in Depression Scale (QLDS). J Affect Disord 2001; 63: 189-199.

51. Sanders C, Egger M, Tallon D, Frankel S. Reporting on quality of life in randomised controlled trials. BMJ 1998; 317: 1191-1194.

52. World Health Organization. The International Classification of Impairments, Disabilities and Handicaps. Geneva, World Health Organization, 1980.

53. Doward LC, McKenna SP, Meads DM, Ratcliffe J, Whalley $\mathrm{D}$, Langley PC. Investigation into the feasibility of deriving relative and absolute utility from the Recurrent Genital Herpes Quality of Life questionnaire (RGHQoL). Value Health 2002; 5: 573-574.

54. McKenna SP, Whalley D, Doward LC. Which outcomes are important in schizophrenia trials? Int J Methods Psychiatr Res 2000; 9: S58-S67.

55. Patrick DL, Bush JW, Chen MM. Methods for measuring levels of well-being for a health status index. Health Serv Res 1973; 8: 228-245.

56. Hunt SM, McKenna SP. The QLDS: a scale for the measurement of quality of life in depression. Health Policy 1992; 22: 307-319.

57. Berzon R, Hays RD, Shumaker SA. International use, application and performance of health-related quality of life instruments. Qual Life Res 1993; 2: 367-368.

58. Cacoub P, Dorent R, Maistre G, et al. Endothelin-1 in primary pulmonary hypertension and Eisenmenger syndrome. Am J Cardiol 1993; 71: 448-450.

59. Langleben D, Barst RJ, Badesch $\mathrm{D}$, et al. Continuous infusion of epoprostenol improves the net balance between pulmonary endothelin- 1 clearance and release in primary pulmonary hypertension. Circulation 1999; 99: 3266-3271.

60. Rubens C, Ewert R, Halank M, et al. Big endothelin-1 and endothelin-1 plasma levels are correlated with the severity of primary pulmonary hypertension. Chest 2001; 120: 15621569.

61. Stewart DJ, Levy RD, Cernacek P, Langleben D. Increased plasma endothelin-1 in pulmonary hypertension: marker or mediator of disease? Ann Intern Med 1991; 114: 464 469.

62. Wilkens H, Bauer M, Forestier N, et al. Influence of inhaled iloprost on transpulmonary gradient of big endothelin in patients with pulmonary hypertension. Circulation 2003; 107: 1509-1513.

63. Christman BW, McPherson $\mathrm{CD}$, Newman $\mathrm{JH}$, et al. An imbalance between excretion of thromboxane and prostacyclin metabolites in pulmonary hypertension. $N$ Engl $\mathrm{J} \mathrm{Med}$ 1992; 327: 70-75.

64. Friedman R, Mears JG, Barst RJ. Continuous injection of prostacyclin normalizes plasma markers of endothelial cell injury and platelet aggregation in primary pulmonary hypertension. Circulation 1997; 96: 2782-2784.

65. Ghofrani HA, Wiedemann R, Rose F, et al. Lung cGMP release subsequent to $\mathrm{NO}$ inhalation in pulmonary hypertension: responders versus nonresponders. Eur Respir J 2002; 19: 664-671.

66. Bogdan M, Humbert M, Francoual J, et al. Urinary cGMP concentrations in severe primary pulmonary hypertension. Thorax 1998; 53: 1059-1062.

67. Lopes AA, Maeda NY. Circulating von Willebrand factor antigen as a predictor of short-term prognosis in pulmonary hypertension. Chest 1998; 114: 1276-1282.

68. Veyradier A, Nishikubo T, Humbert M, et al. Improvement of von Willebrand factor proteolysis after prostacyclin infusion in severe pulmonary arterial hypertension. Circulation 2000; 102: 2460-2462.

69. Shitrit D, Bendayan D, Rudensky B, et al. Significance of a plasma d-dimer test in patients with primary pulmonary hypertension. Chest 2002; 122: 1674-1678.

70. Hervé P, Launay JM, Scrobohaci ML, et al. Increased plasma serotonin in primary pulmonary hypertension. $\mathrm{Am}$ J Med 1995; 99: 249-254.

71. Kéreveur A, Callebert J, Humbert M, et al. High plasma serotonin levels in primary pulmonary hypertension: effect of long-term epoprostenol (prostacyclin) therapy. Arterioscler Thromb Vasc Biol 2000; 20: 2233-2239.

72. Humbert M, Monti G, Brenot F, et al. Increased interleukin1 and interleukin- 6 serum concentrations in severe primary pulmonary hypertension. Am J Respir Crit Care Med 1995; 151: $1628-1631$.

73. Nagaya $\mathbf{N}$, Nishikimi $\mathrm{T}$, Uematsu $\mathbf{M}$, et al. Plasma brain natriuretic peptide as a prognostic indicator in patients with primary pulmonary hypertension. Circulation 2000; 102: 865-870.

74. Wiedemann R, Ghofrani HA, Weissmann N, et al. Atrial natriuretic peptide in severe primary and nonprimary pulmonary hypertension: response to iloprost inhalation. J Am Coll Cardiol 2001; 38: 1130-1136.

75. Torbicki A, Kurzyna M, Kuca P, et al. Detectable serum cardiac troponin $\mathrm{T}$ as a marker of poor prognosis among patients with chronic precapillary pulmonary hypertension. Circulation 2003; 108: 844-848.

76. Nagaya N, Uematsu M, Satoh T, et al. Serum uric acid levels correlate with the severity and the mortality of primary pulmonary hypertension. Am J Respir Crit Care Med 1999; 160: 487-492.

77. Cracowski JL, Cracowski C, Bessard G, et al. Increased lipid peroxidation in patients with pulmonary hypertension. $\mathrm{Am}$ J Respir Crit Care Med 2001; 164: 1038-1042. 